\title{
Pain Management of Amazon Indigenous Peoples: A Community-Based Study
}

\author{
Elaine Barbosa de Moraes' \\ Daniela Reis Dal Fabbro² \\ Leticia Bernardes de Oliveira ${ }^{2}$ \\ Eliseth Ribeiro Leão $\mathbb{D I}^{2}$ \\ 'Israeli Faculty of Health Sciences Albert \\ Einstein, Hospital Israelita Albert \\ Einstein, São Paulo, São Paulo, Brazil; \\ ${ }^{2}$ Research Institute, Hospital Israelita \\ Albert Einstein, São Paulo, São Paulo, \\ Brazil
}

Purpose: Indigenous peoples are vulnerable populations that live in remote areas of the Amazon forest with limited access to health-care services. Underreporting and undertreatment of pain is a common event in the general population but little is known about these issues in indigenous peoples. The aim of this study was to investigate the characteristics and cultural aspects of pain management in five ethnicities of the Brazilian Amazon.

Materials and Methods: Cross-sectional study carried out with adult indigenous individuals from five ethnicities of the Brazilian Amazon over two scientific expeditions (June-July/2017 and February-March/2019). Pain assessment included etiology, intensity, duration, aggravating and alleviating factors, body location, impact of pain on activities of daily living, and treatment. Results: Ninety indigenous individuals with a mean age of $41.42 \pm 19.59$ years (range 1998 years) and median age of 37 years participated in the study. Sixty-four individuals $(71.1 \%)$ reported experiencing pain at the time of interview with intermittent musculoskeletal pain of strong intensity being the more prevalent (back pain: $45.3 \%$, joint pain: $43.7 \%$ ) followed by headache $(26.5 \%)$. The main alleviating factors reported were traditional indigenous medicine $(21.0 \%)$ and rest $(30.0 \%)$, and physical exertion was the main aggravating factor $(69.0 \%)$. Most study participants reported that pain affected their mood, activities of daily living, and sleep and that they used both traditional indigenous medicine (78.0\%) and conventional medicine $(81.0 \%)$ for pain relief.

Conclusion: Musculoskeletal pain is prevalent among indigenous individuals, affects their quality of life, and is partly attributed to their lifestyle. Cultural aspects mediating the pain experience were observed. Traditional indigenous medicine for pain relief remains partially preserved among the ethnic groups investigated. The findings of this study can help improve the delivery care to these vulnerable populations.

Keywords: indigenous peoples, traditional medicine, pain management, public health, vulnerable population, transcultural nursing

\section{Introduction}

Pain is a global public health issue. ${ }^{1}$ A study with more than 6 million patients revealed the occurrence of high prevalence of back pain (74.7\%), degenerative spine disease $(63.6 \%)$, neuritis/radiculitis $(52.8 \%)$, and chronic pain $(10.4 \%){ }^{2}$ However, it should be noted that pain prevalence tends to vary between different countries. One of the largest studies of pain prevalence in low- and middle-income countries showed that $28 \%$ of people have chronic pain. ${ }^{3}$ The study also revealed an association between illiteracy and more prevalent pain. The few existing studies ${ }^{4-7}$ of pain in vulnerable populations indicate that the prevalence of pain tends to be higher than that found in developing countries. The prevalence of pain among indigenous populations is also poorly established. ${ }^{8}$
Correspondence: Eliseth Ribeiro Leão Research Institute, Hospital Israelita Albert Einstein, São Paulo, São Paulo, Brazil

Tel +5511996186489

Fax +551121510273

Email eliseth.leao@einstein.br 
The current situation of indigenous peoples has been a concern of the United Nations. ${ }^{9}$ Indigenous peoples are estimated to be about 370 million (approximately 5\% of the world population) in about 90 countries ${ }^{10}$ and make up about one third of the world's 900 million extremely poor rural people. ${ }^{9}$ Brazil has approximately one million indigenous individuals distributed throughout the country, with around 306 thousand living in the Amazon region. ${ }^{11}$

Indigenous peoples are among the most marginalized peoples globally and are generally isolated in their countries, both politically and socially, due to the geographic location of their communities, their histories, cultures, languages, and traditions. Health data on indigenous populations are fragmented and incomplete, especially about pain caused by health conditions. ${ }^{9}$

The experience of pain is quite complex and influenced by the socio-cultural contexts. ${ }^{12}$ Because it is a highly subjective and personal experience, only the individual experiencing pain can describe it to a health-care provider. Collecting data on the perception of pain and behaviors experienced by indigenous peoples has its own difficulties in Brazil, as there are 305 ethnic groups who speak 274 different languages in the country that. ${ }^{11}$ This is a vulnerable and often neglected population and few studies have investigated pain in indigenous peoples, also at the international level. ${ }^{13,14}$

The 2030 Agenda for Sustainable Development adopted the motto "leave no one behind", with a strong emphasis on the most disadvantaged members of society. ${ }^{15}$ But to ensure that this commitment translates into effective action, it is necessary to know the target populations, especially indigenous peoples who avoid contact with modern society and live in isolation.

A cultural approach is necessary to understand pain in indigenous peoples. This is the first study on the cultural aspects of pain management among indigenous peoples in Brazil which could help to develop a framework for the delivery of culturally competent care. Thus, we aimed to examine the characteristics and cultural aspects of pain management in five ethnic groups in the Brazilian Amazon and the traditional healing practices used for pain management and control.

\section{Materials and Methods}

This is a cross-sectional observational field study.

\section{Participants}

The recruitment of study participants was carried out in the field as follows: research objectives, inclusion criteria, and the data collection procedures of the study were explained to the indigenous leaders at a communal meeting (with indigenous cultural procedures adopted) in each village. It is worth mentioning that the first volunteers of the indigenous groups were of elders and leaders who, after taking part in the study, supported the free participation of the other members of the village.

Four women refused to participate because their husbands were not at home and they were not allowed to talk to strangers (Ashaninka). Three Matis women also refused at first, but after they played football with one of the researchers, they asked to be included in the study. One individual from the Matis ethnic group was excluded because presented answers to what was asked that made no sense.

Ninety adult indigenous individuals of the Matis, Marubo, Kanamary, Ashaninka, and Huni Kuin ethnicities were included (a convenience sample). One old man (Kanamary) who could not understand the translator or who gave confusing answers during the interviews was excluded from the analysis.

\section{Ethical and Legal Aspects}

Investigators conducting research with indigenous peoples are required to submit a detailed application form, including the following documents: a) Permit for Research in Indigenous Lands signed by all tribal leaderships, granting permission for the use of all photographic, audio and video records; b) a non-commercial license from the National Indian Foundation (FUNAI) prohibiting any commercial use of the data.

Permission for research activities was granted by indigenous chiefs and village leaders during communal assemblies held in each village. After institutional ethical review, the study was approved by FUNAI and the National Research Ethics Committee. After a detailed review of the documentation and project materials, the FUNAI presidency issued a permit to enter indigenous lands for research purposes.

The study was conducted in accordance with Brazilian law for research with humans and the Declaration of Helsinki and approved by the National Commission for Research Ethics (Certificate for Ethical Appreciation number 62604716.7.0000.0071). Participants signed an informed consent form or provided their fingerprint in the presence of the village leaders as per the requirements of Resolution n. 304 of the National Health Council (CNS). 
The researchers ensured the confidentiality and protection of the image of participants and the nonstigmatization, and that the information would not be used to means other than the present study, as explained to them.

The same procedures were performed for the two scientific expeditions.

\section{Description of Research Environment}

The Leininger Expedition and the Iracema Expedition were carried out in June 2017 and February 2019, respectively, totaling 38 days in the Amazon forest of Javari Valley (Amazonas) and in the indigenous lands of Amônia river and Jordão river (Acre) to visit seven villages where five ethnicities lived. Each of these regions has an indigenous health-care service but access is very limited, since they need to travel by canoe for days to the cities where these services are located. A boat with health professionals visits the region a few times a year. In the region of Javari Valley there is a health-station in one of the villages of the Matis with a nurse, a nursing technician and two microscopists, who provide basic assistance and using very limited resources.

The Javari Valley Indigenous Land is located in a triple border region between Brazil, Peru and Colombia and the indigenous lands of Acre, in a border region between Brazil and Peru. The villages are located in an inhospitable region, with dense and closed forest, surrounded by biological risks and with low security (presence of loggers, miners, drug traffickers). There is low investment in material resources and specialized professional qualification for the few who venture to provide health care in these regions.

In general, communication between the villages and non-indigenous populations and other tribes is very restricted, first because they are in remote regions (ten days of navigation on average), and due to the option of these peoples to remain more isolated, with the exception of some younger leaders who are more mobile, but who are also restricted by travel conditions and costs.

The access of the research team to access the study participants was quite challenging and involved air travelling $(17,034 \mathrm{~km}$ in commercial planes and air taxis), land transport, river transport by motorboat and indigenous canoes $(5027 \mathrm{~km})$ and long walks through the Amazon rainforest.

The expedition teams were composed of two female investigators, two boatmen, and two logistics specialists, all, without exception, having completed jungle training courses in addition to four local indigenous guides for each stage of the two expeditions.

\section{Data Collection and Analysis}

Considering that there is no validated pain assessment instrument for Brazilian indigenous populations and considering the many indigenous languages (274), we developed a questionnaire with the main aspects that make up pain assessment: ${ }^{16}$ etiology (what had triggered the painful condition), intensity (weak, moderate or severe), location (which region of the body was in pain), duration (how long the pain was in; pain that has lasted for at least three months was considered chronic pain), ${ }^{17}$ aggravating or alleviating factors (what improved or worsened pain), the impact of pain on activities of daily living (sleep, daily activities, mood and relationships) and treatments (which were used to pain relief - indigenous and non-indigenous remedies). In addition, we used a male and female body diagram where participants of both sexes could recognize themselves and point out the location of their pain. Moreover, it was also requested that each individual pointed at the body's own pain location for a double check.

The questions were clearly written in plain Portuguese and phrased in a way to facilitate translation by the indigenous interpreter and provide easier understanding to the indigenous participant. Five indigenous health-care agents or teachers were recruited as translators in each village.

Self-report is the gold standard for pain asessment ${ }^{9}$ and was used in this study due to the lack of an assessment tool validated for indigenous peoples and despite its inherent limitations in a context that requires mediation. In order to minimize the bias in participants' responses in pain assessment, the researchers also sought to be attentive to nonverbal communication during the interview (the indigenous people, also because they do not speak Portuguese, try to pass through the expression and gestures of the report of their pain). This careful observation was used to further explore the dialogue with the translator in search of greater certainty that the translated content would be closer to the indigenous story. This was particularly useful when referring to the intensity of the pain (facial expression of suffering). A relationship was established during the days of conviviality in the village where security was given so that they would have a reliable environment to share the painful experience. The researchers learned some keywords related to the painful experience prior to the interviews, taught by the translator that 
were used to listen carefully to the reports of the study participants.

Data collection was performed at times and locations established by the village leaders.

Descriptive analysis was performed by ethnicity, but ethnic groups were named by groups from 1 to 5 at random, in order to keep the identification of individuals private (Table 1). The age range of the participants followed the criteria of the World Health Organization (WHO). ${ }^{18}$

Categorical variables are reported as absolute and relative frequencies, whereas quantitative variables are reported as mean \pm standard deviation, median, and range. Simple chi-square or Fisher's exact tests were performed depending on the sample size in each category. All analyses were performed using R Core Team (2017). Data were considered significant at $\mathrm{p}<0.05$.

\section{Results}

Ninety indigenous individuals (45 women) participated in the study. Mean age was $41.42 \pm 19.59$ years (range 19-98 years) and median age was 37 years, ie, half of the study participants were 37 years old or younger.

Twenty-nine $(32.2 \%)$ of the 90 participants were Ashaninka, $20 \quad(22.2 \%)$ Huni Kuin, $18 \quad(20.0 \%)$ Kanamary, four (4.4\%) Marubo, and 19 (21.1\%) Matis.

Sixty-four $(71.1 \%)$ indigenous individuals reported speaking Portuguese 64 (71.1\%) and 60 (66.7\%) reported they could write their name.

\section{Indigenous Perspectives on Pain}

A history of pain was reported by 71 (78.9\%) participants. Sixty-four $(71.1 \%$ - 28 women and 26 men) participants reported experiencing pain at the time of the interview with musculoskeletal pain being the more prevalent (back pain: $45.3 \%$, joint pain: $43.7 \%$ ), followed by headache $(26.5 \%)$ (Table 1$)$.

The distribution of pain by age group following the WHO classification was $18-44$ years $(71 \%), 45-49$ years (11\%), 60-74 years (11\%), 75-89 years $(4 \%)$ and $90+$ (3\%), and pain is therefore predominant among young adults, who also reported feeling pain at the time of the interview (44\%).

There was no statistical difference by sex in relation to the presence of pain at the time of the interview (p-value $=$ 0.077). However, a difference was observed for the variables: "Joint Pain in the upper limbs" (p-value = 0.028), and "Pelvic Pain, previous pain" ( $\mathrm{p}$-value $=0.002$ ). Among men, $7.9 \%$ reported previous upper limbs joint pain, while in the group of women the percentage was $26.8 \%$; and among men, $31.6 \%$ reported previous pelvic pain, while in the group of women the percentage was $2.49 \%$.

Table 2 shows that half of study participants experienced severe and intermittent pain.

As for the time spent living with pain, 20\% reported less than 3 months, $28 \%$ more than three months (chronic pain), but $52 \%$ were unable to estimate the duration of the pain experience.

The main descriptor used to describe pain, especially by the Matis, was burning (18.2\%). The Huni Kuin, Ashaninka, and Kanamary mainly described pain as heavy (16.9\%), few participants described pain as stabbing, piercing, throbbing, and radiating. Various other pain descriptors, including shooting, thickening, numb, pinching, tingling, tiring, pressure stinging, burning, and hot

Table I Pain Location at the Time of Interview $(N=64)$

\begin{tabular}{|c|c|c|c|c|c|c|}
\hline Variables & Total & Group I & Group 2 & Group 3 & Group 4 & Group 5 \\
\hline Spine - n (\%) & $29(45.3)$ & II (I7.2) & $7(11)$ & $3(4.6)$ & $0(0.0)$ & $8(12.5)$ \\
\hline Joints - n (\%) & $28(43.7)$ & $7(11.0)$ & $6(9.3)$ & $7(11.0)$ & $3(4.6)$ & $5(7.8)$ \\
\hline Head - n (\%) & $17(26.5)$ & $5(7.8)$ & $7(11.0)$ & $\mathrm{I}(\mathrm{I} .5)$ & $\mathrm{I}(\mathrm{I} .5)$ & $3(4.6)$ \\
\hline Lower limbs- $n$ (\%) & $16(25.0)$ & $3(4.6)$ & $3(4.6)$ & $3(4.6)$ & $3(4.6)$ & $4(6.2)$ \\
\hline Abdomen - n (\%) & II (I7.0) & $5(7.8)$ & $\mathrm{I}(\mathrm{I} .5)$ & $\mathrm{I}(\mathrm{I} .5)$ & $0(0.0)$ & $4(6.2)$ \\
\hline Chest - n (\%) & $10(15.5)$ & $5(7.8)$ & $3(4.6)$ & $0(0.0)$ & $0(0.0)$ & $2(3.0)$ \\
\hline Stomach - n (\%) & $9(14.0)$ & $3(4.6)$ & $\mathrm{I}(\mathrm{I} .5)$ & $2(3.0)$ & $0(0.0)$ & $2(3.0)$ \\
\hline Upper limbs - n (\%) & $6(9.4)$ & $\mathrm{I}(\mathrm{I} .5)$ & $\mathrm{I}(\mathrm{I} .5)$ & $2(3.0)$ & $0(0.0)$ & $2(3.0)$ \\
\hline Pelvis - n (\%) & $5(7.8)$ & $4(6.2)$ & I (I.5) & $0(0.0)$ & $0(0.0)$ & $0(0.0)$ \\
\hline Tooth - n (\%) & $2(3.0)$ & $0(0.0)$ & $\mathrm{I}(\mathrm{I} .5)$ & $0(0.0)$ & $0(0.0)$ & $\mathrm{I}(\mathrm{l} .5)$ \\
\hline Glutes - n (\%) & $2(3.0)$ & $0(0.0)$ & $0(0.0)$ & $2(3.0)$ & $0(0.0)$ & $0(0.0)$ \\
\hline Throat - n (\%) & $\mathrm{I}(\mathrm{I} .5)$ & $0(0.0)$ & $0(0.0)$ & $0(0.0)$ & $0(0.0)$ & $\mathrm{I}(\mathrm{I} .5)$ \\
\hline
\end{tabular}

Note: $\mathrm{N}$ or $\mathrm{n}=$ sample size. 
Table 2 Pain Frequency, Intensity, and Duration

\begin{tabular}{|l|c|}
\hline Variables & Total \\
\hline Intermittent & $26(52.0)$ \\
Constant & $16(32.0)$ \\
Daily & $3(6.0)$ \\
Night & $2(4.0)$ \\
Every 20 days & $2(4.0)$ \\
Monthly & $1(2.0)$ \\
\hline Pain intensity - $\mathrm{n}(\%)(\mathrm{N}=57)$ & \\
Mild & $18(31.6)$ \\
Moderate & $10(17.5)$ \\
Severe & $29(50.9)$ \\
\hline
\end{tabular}

Note: $\mathrm{N}$ or $\mathrm{n}=$ sample size.

were used by less than $10 \%$ of the participants. The time living with pain ranged from days to more than 40 years and was also described as "a very long time" or "many years", but there was great variability in answers which were for the most part unspecific.

The main alleviating factors of pain reported were Traditional Indigenous Medicine (21.0\%) and rest $(30.0 \%)$, whereas physical exertion was the main aggravating factor $(69.0 \%)$.

Most participants reported that their mood, activities of daily living, and sleep were affected by pain (Table 3).

\section{Pain Relief Therapies}

Table 4 shows that both traditional indigenous medicine and white man's medicine (as non-traditional healing practices and medications are called by indigenous individuals) taken either with or without prescription are widely used, regardless of gender, for pain relief. However, when asked if health-care providers ask them about the use of TIM, men showed a significantly higher perception of this questioning compared to women $(p-v a l u e=0.003)$. Among women, $15.9 \%$ reported that health professionals investigate the use of Traditional Indigenous Medicine (TIM), while $45.2 \%$ of men recalled that this theme (use of TIM) came up.

Traditional Indigenous Medicine is characterized mainly by a large diversity of plant extracts made from roots, leaves, and stems that are called by indigenous peoples as "forest medicine", which can be used ground, cooked, in the form of plasters, ointments, baths, foot soaks, via oral ingestion, oral mucosal administration, or even inhaled as in the case of nasal snuff. Pajelança (ie, healing rituals using herbs and prayers, singing, blowing, smoking, and blood-sucking) was mentioned by $11 \%$ of the participants. Use of animal-based medicines made from toxins secreted from glands in amphibian skin, snake lard, and ant bites was also reported. Some of these TIM healing practices are described in Figure 1.

\section{Discussion}

This study investigated the characteristics and cultural aspects of pain and the treatments and healing practices used for pain management and control by indigenous peoples in the Brazilian Amazon.

Indigenous individuals from the five ethnicities experienced mainly musculoskeletal pain, of severe intensity for

Table 3 Effects of Pain on Activities of Daily Living in Indigenous Peoples

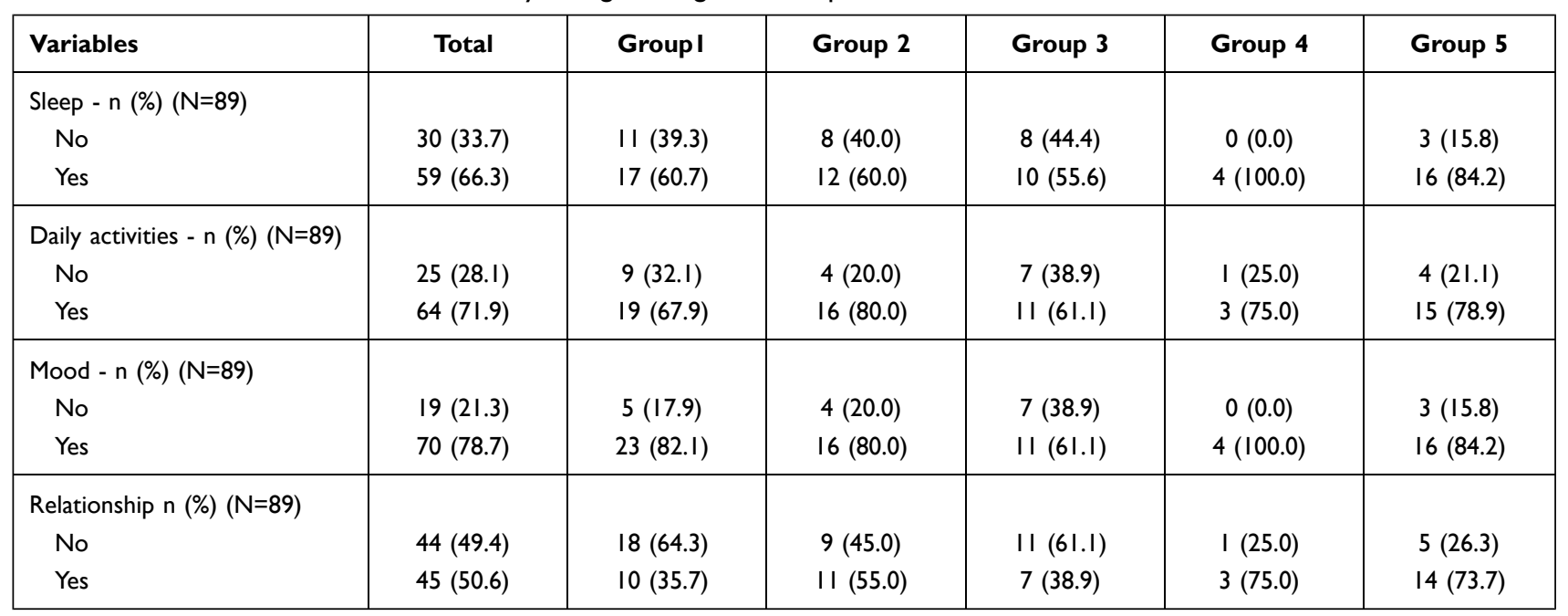

Note: $\mathrm{N}$ or $\mathrm{n}=$ sample size. 
Table 4 Pain Treatment Therapies

\begin{tabular}{|c|c|c|c|c|}
\hline Variables & Total & Female & Male & p-value \\
\hline Traditional Indigenous Medicine - $\mathrm{n}(\%)(\mathrm{N}=90)$ & & & & 0.128 \\
\hline No & $20(22.2)$ & $13(28.9)$ & $7(15.6)$ & \\
\hline Yes & $70(77.8)$ & $32(7 I .1)$ & $38(84.4)$ & \\
\hline Conventional Medicine with medical prescription - n (\%) (N=90) & & & & 0.419 \\
\hline No & $17(18.9)$ & $10(22.2)$ & $7(15.6)$ & \\
\hline Yes & $73(8 I .1)$ & $35(77.8)$ & $38(84.4)$ & \\
\hline Conventional Medicine without medical prescription - $\mathrm{n}(\%)(\mathrm{N}=88)$ & & & & 0.522 \\
\hline No & $45(51.1)$ & $24(54.5)$ & $21(47.7)$ & \\
\hline Yes & $43(48.9)$ & $20(45.5)$ & $23(52.3)$ & \\
\hline Health care providers ask about the use of TIM - $n(\%)(N=86)$ & & & & $0.003^{*}$ \\
\hline No & $60(69.8)$ & $37(84.1)$ & $23(54.8)$ & \\
\hline Yes & $26(30.2)$ & $7(15.9)$ & $19(45.2)$ & \\
\hline Health care providers support the use of TIM - $n(\%)(N=67)$ & & & & 0.067 \\
\hline No & $33(49.3)$ & $19(61.3)$ & $14(38.9)$ & \\
\hline Yes & $34(50.7)$ & $12(38.7)$ & $22(61.1)$ & \\
\hline
\end{tabular}

Notes: $\mathrm{N}$ or $\mathrm{n}=$ sample size; $*$ Significance level $<0.050$.

a large proportion of the study participants, and with a duration suggestive of chronic pain for one third of the cases.
Although all indigenous individuals in the community (including children) are subjected to physical efforts, we observed differences between men and women in terms of

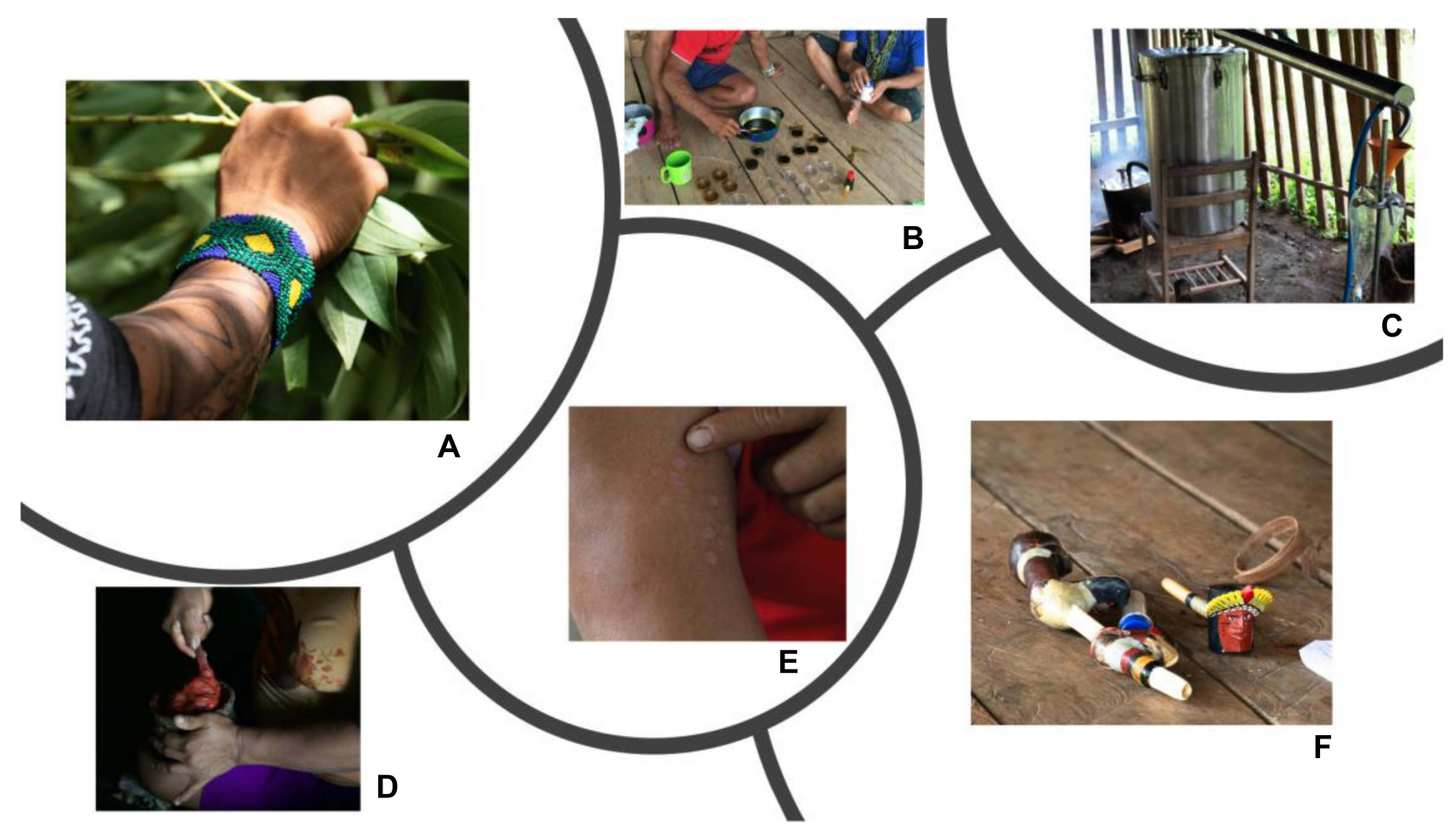

Figure I (A) Collection of leaves for ointment production; (B) preparation of ointment from plant extracts with anti-inflammatory properties; (C) extraction of essential oil for headache treatment; (D) preparation of breu-branco (amescla) resin (Protium heptaphyllum) with annatto powder (Bixa orellana) prayed by the shaman; (E) marks of the use of the toxins secreted from glands in the skin of the giant monkey frog Phyllomedusa bicolor (the "toad vaccine" or "kambô" contains opioid peptides with analgesic properties); and (F) nasal snuff inhalation artifacts. 
the location of pain. Women had about three times more joint pain in their upper limbs than men. These, on the other hand, had about 12 times more pelvic pain than women. This can be explained both by the nature of the activities they carry out and by the gender predisposition. Inguinal hernias are predominantly male ${ }^{19}$ and the prevalence of pain before surgery is high, ${ }^{20}$ but it is difficult to estimate its etiology due to the lack of diagnosis for these individuals.

Literature review including studies done in eight countries in South America identified difficulties in accessing health services closest to the villages; and also identified language and illustrations of health education booklets inappropriate to the indigenous context; difficulty communicating with health professionals; lack of adequate means of transport to health facilities; scarcity of epidemiological data on indigenous villages; lack of information about local indigenous cultures; and fear of discrimination or humiliation by the indigenous patient. The authors highlight the scarcity of studies on indigenous populations and the need for health systems to move towards intercultural medicine. $^{21}$

It was also observed that men talk about 2.7 times more with health professionals about the use of Traditional Indigenous Medicine than women. Social roles among indigenous people are also well defined. With the determination of the public as a masculine space, the antagonistic determination of the sexual identities of indigenous peoples brings a clear demonstration that the role of man is to interact with the outside world in social relations. And women are segregated to the private space, which limits their social relations to the domestic sphere - being limited to taking care of food, the house, children, among other tasks occurring in the private space, so the interaction with individuals outside the village is always more restricted for women. ${ }^{22}$

Differently from what was found in literature, ${ }^{23}$ in the present study, we did not observe any difference between genders for the presence of pain or its intensity. In nonindigenous populations, women report pain at levels more severe than those reported by men, more frequent pain in more areas of the body and pain of longer duration than men. There are gender differences in pain and its relief arise from an interaction of genetic, anatomical, physiological, neuronal, hormonal, psychological and social factors that modulate pain differently in the sexes. ${ }^{24}$ We believe that cultural factors regarding painful behavior in the indigenous population are preponderant, especially for women.
The belief that indigenous women have higher pain tolerance than non-indigenous women was also widespread among the female participants. In Bororo culture, childbirth is an appropriate time for Bororo women to reaffirm their strength as demonstrated by the silence and resignation with which they experience labor. ${ }^{25}$ None of the indigenous women from any of the five ethnicities made any reference to childbirth pain. Daily pain resulting from the traditional indigenous way of living appears to be somewhat accepted as part of life; hence, the reason the cognitive-evaluative component, ie, the symbolic expression of pain, was underrepresented in indigenous individuals' experiences of pain.

In the cultural sphere, pain also has an initiatory function and is present in the rites of passage found in virtually all indigenous cultures, where tolerance to pain signifies the passage to maturity and denotes, for boys, virility and courage that are worthy of the admiration of their community. ${ }^{26}$ Although these rites clearly influence the expression of pain behaviors, we are uncertain whether they have any bearing on individual pain threshold.

The Matis people clearly demonstrate a stoic attitude to pain as evidenced by the use of an assortment of adornments such as face tattoos imitating the jaguar's mustache, sticks pierced through the nose and skin and other ornaments, all involving painful procedures to some degree.

The prevalence of low back and joint pain in adults found in this study $(45.3 \%$ and $43.7 \%$, respectively) is higher than that indicated in other studies for low back pain, which then varies between $12 \%$ and $33 \% .^{27}$ A study with more than 60 thousand Brazilians over 18 years old found a low-back pain prevalence of estimated at $18.5 \%$ (95\% CI: 17.8-19.1). ${ }^{28}$

Even though few studies have addressed the prevalence of pain among indigenous peoples, ${ }^{29}$ a study of the Warao, Kari'ña, and Chaima indigenous people of Venezuela reported a lower prevalence of low-back pain $(17.8 \%)$ and joint upper limb pain $(9.5 \%) .{ }^{30}$ A study on American Indian and Alaska Native populations also reported higher prevalence of low-back pain than the general population of the United States (35 vs 26.4\%) and also for headache $(22.9$ vs $15.5 \%),{ }^{31}$ suggesting that chronic pain in indigenous peoples may be partly attributed to their lifestyle. Both low-back pain and headache pain of international studies were lower than those found in the present study. Comparing our data with data from the general Brazilian population, the Brazilian indigenous peoples, similarly to Native Americans and Alaska, also 
have a higher prevalence of low back pain (45.3 vs $21.1 \%$ ) and headache (26.5 vs $15 \%) .{ }^{3}$ If access to health to natives from other parts of the world, in which the majority live in urban areas $(66 \%)$ is already considered difficult and has implications for the identification and management of pain, ${ }^{31}$ in the case of Brazilian Indians in this study this situation seems much more critical, as WHO itself recognizes that one of the biggest challenges in Brazil is offering health care to remote communities that live in the depths of the Amazon jungle, where roads are few and medical teams need to travel many hours by boat to take care of them. ${ }^{32}$

Chronic musculoskeletal pain has been shown to adversely affect the health-related quality of life, functional ability, and emotional well-being of patients. ${ }^{33,34}$

The cause of musculoskeletal pain communicated by the participants appears to be related to the challenges of rural work and the heavy daily workloads, especially the overhead weight that is carried by both men and women and the long distances they walk in the forest in pursuit of game and plants. These activities require repetitive efforts and inadequate postures which are usually associated with low back pain as widely reported for rural workers. ${ }^{35-38}$

A systematic review shows that, although the prevalence of pain increases with age, the relationship is not linear and stabilizes around the age of sixty. Our findings do not allow any inference in this regard, since participants were young adults. ${ }^{39}$

Pain assessment in indigenous peoples is critical to optimal pain management interventions but its results should be interpreted with caution in patients with language barriers. In the current study, all interviews were conducted in Portuguese and translated by an indigenous translator/interpreter. In addition, some ways used to assess pain, in terms of quantifying it in degrees of intensity, seemed to be understood differently by the indigenous people. For most of them, the pain is either severe or weak, there is no middle term. Likewise, we observed that estimating temporal characteristics of pain also lacks precision. For them, the experiences boil down to an idea of little time or a lot of time.

To report one's perception of pain is difficult to everyone, therefore pain measurement instruments have been developed to meet this need. For indigenous peoples, pain measurement may be even harder due to language and cultural barriers and the fact that no pain measurement tool has ever been developed having these populations in mind. This difficulty has been previously reported. ${ }^{40}$
Indigenous individuals used spontaneous pain descriptors, since there is no semantic pain assessment tool validated for indigenous peoples. The main pain descriptors used among participants were "burning" and "heavy". In contrast, descriptors associated with the evaluative and emotional dimension of pain were rarely used - one Kanamary individual described pain as "tired", and "emotional" pain was associated with feelings of longing or rejection as communicated by one Ashaninka and one Huni Kuin individual, respectively.

The affective-motivational component of pain concerns the emotions that come into play during the experience of pain and reaction to pain - which was culturally mediated among indigenous individuals. Social learning is essential in the development of the meanings attributed to pain in the cultural context. This learning begins within the family unit and is modified, integrated, and maintained through broader social life. ${ }^{41}$

In this study, participants reported that pain affected their overall quality of life and daily living and had the greatest impact on mood, activities of daily living, sleep, and relationships. Nevertheless, in face of their harsh living conditions, indigenous individuals appear to minimize the impact of pain because despite of it and the fact that exertional activities of daily living are aggravating factors, they cannot refrain from taking part in these activities. Non-indigenous people consider musculoskeletal pain to adversely affect the health-related quality of life, functional ability, and emotional well-being. ${ }^{33,34}$

Rest and Traditional Indigenous Medicine (TIM) were the main alleviating factors reported by participants. However, the results showed that fewer participants turned to TIM $(78.0 \%)$ than to conventional medicine $(81.0 \%)$ across the five ethnicities, and only a minority of participants described TIM as an alleviating factor. The only exception was in the Huni Kuin and Matis, who live in more isolated regions of the Amazon, indicating that ancestral knowledge may be better preserved in these cultures as a result of their isolation. The use of different allopathic approaches in combination with TIM has been reported in numerous ethnicities from other countries ${ }^{42}$ and understanding the pain coping strategies of indigenous peoples can serve as a starting point for developing measures to prevent and reduce misuse and abuse of prescription medication and other drugs in indigenous communities. ${ }^{43}$

Bark and leaves from a myriad of species were mentioned in their indigenous names and could be neither 
translated nor identified, which would have required specialized expertise and in any case was outside the scope of this study. Participants also had reservations about sharing their knowledge and are concerned about misappropriation, which is not an unjustified concern among Amazonian indigenous tribes.

Still, we were given access to a mixture of breu-branco resin colored with annatto powder used as a topical pain reliever as previously confirmed elsewhere. The breubranco resin oil is known for its antimicrobial, antiinflammatory, and anesthetic activity. ${ }^{44,45}$ Powder extracted from annatto seed is known for its scar healing effects whereas its leaves have anti-inflammatory properties. $^{46,47}$ Toad vaccine, although widely used for pain relief, is highly toxic. ${ }^{48}$

We also witnessed the consumption of snuff, a longstanding cultural and spiritual tradition of the tribes in the Amazon. Snuff is a powdered preparation of tobacco leaves, herbs, and tree ash. Its effects are dependent on the type of plants and herbs used in the blend but some snuff mixtures are known to cause muscle relaxation. ${ }^{49}$ Snuff is consumed as a consecration after work, to relax, and relieve physical and mental pain. ${ }^{50}$

With the Huni Kuin, we had the opportunity to follow, in its entirety, the process for extraction of essential oils and production of an ointment reportedly with antiinflammatory properties, which reflect the immeasurable knowledge accumulated by this ethnicity with great potential to generate benefits not only for local populations but also for the general population. The potential to positively impact society at large as well as the sustainability of forest peoples is immense.

Morbidity data on indigenous populations are fragmented and incomplete both in Brazil and across the world, which precludes an objective assessment of health indicators, particularly with respect to their pain experiences. There are barriers involving communication and many indigenous patients are unwilling to report their pain because they perceive medical providers as using complex terms and having negative attitudes towards patients. ${ }^{51}$

We are currently faced with the challenge to strengthen research on ethnic health care and develop studies that are suited to the realities experienced by ethnically and culturally diverse populations. Thus, it is strongly recommended efforts to develop culturally appropriate pain assessment tools that fit the needs of indigenous populations. $^{52}$
Conducting pain research with indigenous peoples poses many challenges, including, among others, the lengthy process for applying for permits to enter indigenous lands, raising funds for the costly expeditions, the prolonged stay in villages under poor living conditions, and the scarcity of literature on pain in these populations. Additionally, there were never more than 130 individuals living in each village, including many children. This aspect made it difficult to compare pain in different age groups that deserve to be explored in future studies. There are larger groups, who live on the outskirts of large Amazonian cities, who have already been impacted by the environment where they live (not original) and who already have a lifestyle, eating habits of non-indigenous society and therefore were not explored in this study. These difficulties help explain some of the limitations of the study such as the inclusion of only a small number of individuals due to access difficulties encountered in the field and the lack of a more detailed description of healing rituals, which would have required additional funding and an extended stay in the field to document the traditional practices as they occurred. Moreover, the enormous cultural differences among ethnic groups preclude generalizations from our data, considering that there are more than 300 ethnic groups and 274 different languages existing in the country. Regardless of our small sample, it is very representative of the ethnicities studied, with almost all adult population of the villages being visited. Although we observed a common presence of musculoskeletal pain in the groups studied, it is worth mentioning that studies involving indigenous cultural aspects does not allow generalizations. One ethnic group is culturally different from the other and ethnic groups live in small groups and sometimes even geographically isolated within the same ethnic group, with their own way of life and customs.

Communication mediated by an indigenous translator is also a factor that may have caused some imprecision in obtaining the data. Ideally, researchers should master the language of each ethnicity, which is not feasible and so to minimize this possibility, the researchers elected indigenous health agents or village teachers as translators and repeated the questions exhaustively, whenever non-verbal reading of the interviewee or the size of the verbal speech seemed to indicate some inconsistency with the translation received. Thus, the difficulties in estimating the extent of these issues remain a challenge for researchers. ${ }^{40}$

Some implications of the study were immediate. The main results were compiled, with the help of translators, 
in an educational booklet on pain, which were also presented in indigenous languages: Portuguese-Marubo and Portuguese-Nheengatu (common languages most understood by the indigenous people of Amazonas) - which was distributed to indigenous leaders, to professionals of Health of the Special Indigenous Sanitary Districts of the region and also to the Secretariat of Indigenous Health of the Brazilian Ministry of Health, with a view to contributing to a more adequate assistance in pain management of the studied ethnic groups. The study also provides a methodological path for future researchers and professionals to recognize important cultural aspects in the assessment and treatment of pain. This study can also be replicated for ethnicities not yet studied, what is already planned for the post-pandemic coronavirus period when it is safe to travel to indigenous lands again.

The results suggest that health-care providers should focus their efforts in delivering care that encompasses consideration of cultural aspects not only of the pain experience of indigenous peoples but also of the Traditional Medicine that they turn to for pain relief. The dialogue between conventional and traditional medicine is critical for the provision of culturally competent care and must be encouraged by health-care providers, ie, healthcare providers, who can exercise greater influence in the development of policy aimed at indigenous peoples.

Pain is a global public health issue and while estimates suggest that tens of millions of people suffer from untreated pain globally, access to adequate pain treatment is unevenly distributed worldwide. ${ }^{53}$ Pain-relief treatment is a fundamental human right and there is a conspiracy of silence that urges the creation of a collective voice for those who do not have one. ${ }^{54}$ Changing the reality of access to pain relief requires health-care providers to know and respect the cultural context of the individuals experiencing pain and give greater visibility to the more vulnerable populations.

\section{Conclusion}

Musculoskeletal pain is prevalent among indigenous individuals, affects their quality of life, and is partly attributed to their lifestyle. Cultural aspects mediating the pain experience were observed. Traditional Indigenous Medicine for pain relief remains partially preserved among the ethnic groups investigated.

\section{Acknowledgment}

To São Paulo Research Foundation (FAPESP) for research funding.

\section{Disclosure}

The authors reported no conflicts of interest for this work.

\section{References}

1. Goldberg DS, McGee SJ. Pain as a global public health priority. $B M C$ Public Health. 2011;11:770. doi:10.1186/1471-2458-11-770

2. Murphy KR, Han JL, Yang S, et al. Prevalence of specific types of pain diagnoses in a sample of United States Adults. Pain Physician. 2017;20:E257-E268.

3. Leão Ferreira KAS, Bastos TRPD, Andrade DC, et al. Prevalence of chronic pain in a metropolitan area of a developing country: a population-based study. Arq Neuro-Psiquiatr. 2016;74:990-998. doi:10.1590/0004-282x20160156

4. Campos AG, Victor ES, Seeley M, Leão ER. Pain in Brazilian people experiencing homelessness. PAIN Rep. 2019;4(6):e792. doi:10.1097/ PR9.0000000000000792

5. Azari S, Zevin B, Potter MB. Chronic pain management in vulnerable populations. In: King TE, Wheeler MB, editors. Medical Management of Vulnerable and Underserved Patients: Principles, Practice, and Populations. New York, NY: McGraw-Hill Education; 2016.

6. Green CR, Anderson KO, Baker TA, et al. The unequal burden of pain: confronting racial and ethnic disparities in pain. Pain Med. 2003;4(3):277-294. doi:10.1046/j.1526-4637.2003.03034.x

7. Institute of Medicine (US) Committee on Advancing Pain Research, Care, and Education. Pain as a Public Health Challenge. Relieving pain in America: a blueprint for transforming prevention, care, education, and research. Washington (DC): National Academies Press (US); 2011.

8. Craig KD, Holmes C, Hudspith M, et al. Pain in persons who are marginalized by social conditions. PAIN. 2020;161(2):261-265. doi:10.1097/j.pain.0000000000001719

9. United Nations-Department of Economic and Social Affairs. State of the word's indigenous peoples [e-book]. Nova York; 2009. Available from: http://www.un.org/esa/socdev/unpfii/documents/SOWIP/en/ SOWIP_web.pdf. Accessed April 25, 2018.

10. 10 things to know about indigenous peoples [homepage on the Internet]. United Nations Development Programme; 2019. Available from: https://stories.undp.org/10-things-we-all-should-know-aboutindigenous-people. Accessed March 24, 2021.

11. Instituto Brasileiro de Geografia e Estatística. Estudos especiais: o Brasil indígena: característica sociodemográficas e domiciliares. Censo Demográfico [Internet]; 2010. Disponível em: https://indigenas.ibge.gov. br/estudos-especiais-3/o-brasil-indigena/caracteristica-socidemograficas -e-domiciliares. citado 2016 Out 18. Portuguese.

12. Holt S, Waterfield J. Cultural aspects of pain: a study of Indian Asian women in the UK. Musculoskeletal Care. 2018;16:260-268. doi:10. $1002 / \mathrm{msc} .1229$

13. Incayawar M, Saucier JF. Exploring pain in the Andes-learning from the Quichua (Inca) people experience. Postgraduate Medicine. 2015;127(4):368-375. doi:10.1080/00325481.2015.1015395.

14. Lafontaine A. Indigenous health disparities: a challenge and an opportunity. Can J Surg. 2018;61(5):300-301. doi:10.1503/cjs.01 1718

15. United Nations. Committee for development policy; 2018. Available from: https://sustainabledevelopment.un.org/content/documents/ 2754713_July_PM_2._Leaving_no_one_behind_Summary_from UN_Committee_for_Development_Policy.pdf. Accessed June 17, $202 \overline{1}$.

16. Ahlers SJ, van Gulik L, van der Veen AM, et al. Comparison of different pain scoring systems in critically ill patients in a general ICU. Critc Care. 2008;12(1):R15. doi:10.1186/cc6789

17. Geneen LJ, Moore RA, Clarke C, Martin D, Colvin LA, Smith BH. Physical activity and exercise for chronic pain in adults: an overview of Cochrane Reviews. Cochrane Database Syst Rev. 2017;1: CD011279. doi:10.1002/14651858.CD011279.pub2 
18. Antunes PC, Silva AM. Elements about the Middle Age conception, in the human Aging process. Rev Kairos. 2013;16(5):123-140.

19. Ramji AN. Anthropology of Inguinal Hernia. Int J Contemp Med Res. 2019;6(5):E30-E34.

20. Maliska G, Mello ALP, Amaral RP, Bischoff C. Evaluation of the impact of chronic pain on patients' quality of life before and after inguinal hernioplasty. Rev Med. 2019;98(1):40-45.

21. Sandes LFF, Freitas DA, Souza MFNS, Leite KBS. Primary health care for South-American indigenous peoples: an integrative review of the literature. Rev Panam Salud Publica. 2018;42:e163. doi:10. 26633/RPSP.2018.163

22. Gomes JC, Almeida KP, Silva VB. Porque a escola indígena é masculina? Rev Eletrônica Mestr Educ Ambient. 2012; 29:1-15. Portuguese.

23. Samulowitz A, Gremyr I, Eriksson E, Hensing G. "Brave men" and "emotional women": a theory-guided literature review on gender bias in health care and gendered norms towards patients with chronic pain. Pain Res Manag. 2018;6358624. doi:10.1155/2018/ 6358624

24. Pieretti S, Giannuario A, Giovannandrea R, et al. Gender differences in pain and its relief. Ann Ist Super Sanità. 2016;52(2):184-189. doi:10.4415/ANN_16_02_09

25. Medeiros RM, Grando BS. Analysis Bororo birth: cultural aspects of labor pain. O Mundo Da Saúde. 2016;40(2):160-168.

26. Rangel LH. Da infância ao amadurecimento: uma reflexão sobre rituais de iniciação. Interface Comun Saúde Educ. 1999;3 (5):147-152. (). doi:10.1590/S1414-32831999000200019

27. Meucci RD, Fassa AG, Faria NMX. Prevalence of chronic low back pain: systematic review. Rev Saúde Pública. 2015;49:73. doi:10. 1590/S0034-8910.2015049005874

28. Romero DE, Santana D, Borges P, et al. Prevalence, associated factors, and limitations related to chronic back problems in adults and elderly in Brazil. Cad Saúde Pública. 2018;34(2):e00012817. doi:10.1590/0102-311X00012817

29. Alvarez-Nemegyei J, Peláez-Ballestas I, Goñi M, et al. Prevalence of rheumatic regional pain syndromes in Latin-American indigenous groups: a census study based on COPCORD methodology and syndrome-specific diagnostic criteria. Clin Rheumatol. 2016;35: 63-70. doi:10.1007/s10067-016-3188-y

30. Granados Y, Rosillo C, Cedeño L, et al. Prevalence of musculoskeletal disorders and rheumatic disease in the Warao, Kari'ña, and Chaima indigenous populations of Monagas State, Venezuela. Clin Rheumatol. 2016;35(S1):S53-61. doi:10.1007/s10067-016-3194-0

31. Jimenez N, Garroutte E, Kundu A, Morales L, Buchwald D. A review of the experience, epidemiology, and management of pain among American Indian, Alaska Native, and Aboriginal Canadian Peoples. J Pain. 2011;12(5):511-522. doi:10.1016/j. jpain.2010.12.002

32. From warehouse to remote indigenous communities: the journey of vaccines in Brazil [homepage on the Internet]. World Health Organization; 2017. Available from: https://www.who.int/news-room/fea ture-stories/detail/from-warehouse-to-remote-indigenous-communitiesthe-journey-of-vaccines-in-brazil. Accessed June 17, 2021.

33. Siebra MM, de Vasconcelos TB. Quality of life and mood state of chronic pain patients. Rev Dor. 2017;18(1):43-46. doi:10.5935/18060013.20170010

34. Salvetti M, Pimenta C. Chronic pain and the belief in self-efficacy. Rev Esc Enferm USP. 2007;41(1):135-140. doi:10.1590/S008062342007000100018

35. Davis KG, Kotowski SE. Understanding the ergonomic risk for musculoskeletal disorders in the United States agricultural sector. Am J Ind Med. 2007;50(7):501-511. doi:10.1002/ajim.20479

36. Holmberg S, Thelin A, Stiernström E, Svärdsudd K. The impact of physical work exposure on musculoskeletal symptoms among farmers and rural non-farmers. A population-based study. Ann Agric Environ Med. 2003;10(2):179-184.
37. Taechasubamorn P, Nopkesorn T, Pannarunothai S. Prevalence of low back pain among rice farmers in a rural community in Thailand. $J$ Med Assoc Thai. 2011;94(5):616-621.

38. Silva MRD, Ferretti F, Lutinski JA. Low back pain, muscle flexibility and relationship with the level of physical activity of rural workers. Saúde Em Debate. 2017;41(112):183-194. doi:10.1590/0103-1104 201711215

39. Manek NJ, MacGregor J. Epidemiology of back disorders: prevalence, risk factors, and prognosis. Curr Opin Intern Med. 2005;4:324-330. doi:10.1097/01.bor.0000154215.08986.06

40. Arthur L, Rolan P. A systematic review of western medicine's understanding of pain experience, expression, assessment, and management for Australian Aboriginal and Torres Strait Islander Peoples. PAIN Rep. 2019;4(6):e764. doi:10.1097/PR9.0000000000000764

41. Pimenta CA, Portnoi AG. Dor e cultura. Portuguese. In: Carvalho MM, editor. Dor: Um Estudo Multidisciplinar. São Paulo: Summus; 1999:159-173.

42. Haozous EA, Doorenbos AZ, Stoner S. Pain management experiences and the acceptability of cognitive behavioral strategies among American indians and Alaska natives. J Transcult Nurs. 2016;27 (3):233-240. doi:10.1177/1043659614558454

43. Luna JAA, Moore RS, Calac DJ, Grube JW, McGaffigan RP. Practices surrounding pain management among American Indians and Alaska natives in rural Southern California: an Exploratory Study. J Rural Health. 2019;35(1):133-138. doi:10.1111/jrh.12327

44. Mobin M, De Lima SG, Almeida LTG, et al. MDGC-MS analysis of essential oils from Protium heptaphyllum (Aubl.) and their antifungal activity against Candida specie. Rev Bras Plantas Med. 2016;18 (2):531-538. doi:10.1590/1983-084X/15_110

45. Nascimento JE, Reatgui WS, Araújo LS, et al. Evaluation of antioxidant and anti-Helicobacter pylori in vitro potential of medicinal plant extracts popularly used in Amazon. Rev Fitos. 2017;11(2):140-152.

46. Fourie TG, Snyckers FO. A flavone with anti inflammatory activity from the roots of rhus undulata. J Nat Prod. 1984;47(6):1057-1059. doi:10.1021/np50036a037

47. Lima LR, Oliveira TT, Nagem TJ, et al. Bixina, Norbixina e Quercetina e seus efeitos no metabolismo lipídico de coelhos. Braz J Vet Res Anim Sci. 2001;38(4):196-200. doi:10.1590/S141395962001000400010

48. Silva FV, Monteiro WM, Bernarde PS. "Kambô" frog (Phyllomedusa bicolor): use in folk medicine and potential health risks. Rev Soc Bras MedTrop. 2019;52:e20180467. doi:10.1590/ 0037-8682-0467-2018

49. Carvalho JE, Lapa AJ. Pharmacology of an Indian-snuff obtained from Amazonian Maquira sclerophylla. J Ethnopharmacol. 1990;30 (1):43-54. doi:10.1016/0378-8741(90)90016-M

50. Matos MB, Da Silva Nunes M.Medicina tradicional: terapia indígena no estado do Acre. J Amazon Health Sci. 2016;2(1):1-32.

51. Strong J, Nielsen M, Williams M, Huggins J, Sussex R. Quiet about pain: experiences of aboriginal people in two rural communities. Aust J Rural Health. 2015;23(3):181-184. doi:10.1111/ajr.12185

52. Mittinty MM, McNeil DW, Jamieson LM. Limited evidence to measure the impact of chronic pain on health outcomes of Indigenous people. J Psychosom Res. 2018;107:53-54. doi:10.1016/j. jpsychores.2018.02.001

53. "Please, do not make us suffer any more ... "[homepage on the Internet]. New York: Human Rights Watch; 2020. Available from: https://www.hrw.org/report/2009/03/03/please-do-not-make-us-suffer -any-more/access-pain-treatment-human-right. Accessed November 19, 2020.

54. Brennan F, Obs D, Lohman D, Gwyther L. Access to pain management as a human right. AJPH Pain Manage. 2019;109(1):61-65. 


\section{Publish your work in this journal}

The Journal of Pain Research is an international, peer reviewed, open access, online journal that welcomes laboratory and clinical findings in the fields of pain research and the prevention and management of pain. Original research, reviews, symposium reports, hypothesis formation and commentaries are all considered for publication. The manuscript management system is completely online and includes a very quick and fair peer-review system, which is all easy to use. Visit http:// www.dovepress.com/testimonials.php to read real quotes from published authors. 